\title{
Association between Pre-Hospital Prioritization and Outcome of Injuries from Road Traffic Accidents in Makueni County, Kenya
}

\author{
Anthony Wambua Mathulu ${ }^{1^{*}}$, Eliab Seroney Some ${ }^{2}$ and Esther M Ndonga ${ }^{3}$ \\ ${ }^{1}$ Unit Head Nursing/EPI, Department of Health- Government of Makueni County, Mount Kenya University, Kenya \\ ${ }^{2}$ Associate Professor, School of Pharmacy and Health Sciences, United States International University-Africa, Kenya \\ ${ }^{3}$ Public Health Consultant, Director Cherd Africa, Nairobi, Kenya
}

*Corresponding author: Anthony Wambua Mathulu, Unit Head Nursing/EPI, Department of Health- Government of Makueni County, Mount Kenya University, P.O Box 19-90137, Kibwezi, Kenya

\begin{abstract}
Globally, about 1.3 million people die each year and others remain disabled for the rest of their life due to road traffic accidents [1]. In Makueni County, 1450 cases and 74 deaths were reported in 2015 and 2016 [2,3]. The purpose of this study was to provide evidence for development of policies and programmes to reduce case-fatality rate and other complications from road traffic accidents in Kenya. The study employed the mixed method approach and crosssectional study design. Universal sampling was applied for all the consecutive First Responders who assisted casualties attended in hospitals in Makueni. Data was collected from 427 First Responders and 474 casualties. Quantitative data analysis was through Statistical Package for Social Sciences version 25 while qualitative data was through descriptive reports. Study findings indicate a significant $(P$-value $<0.05)$ relationship between outcome of injuries with sorting of casualties and destination triaging determiner. Sorting of casualties was more likely to result to severe injury outcomes (OR 6.447; 95\% Cl (1.249-33.289); $P=0.26)$. The study concluded that nature and outcome of injuries is significantly associated with pre-hospital prioritization and recommends empowerment of First Responders with appropriate skills for better outcomes.
\end{abstract}

\section{Keywords}

Pre-hospital emergency care, Triaging, Prioritization, First responder, Nature and Outcomes of Injuries

\section{List of Abbreviations}

EMS: Emergency Medical Service; HMIS: Health Management Information System

\section{Introduction}

Emergency Medical Services is a term that describes a range of interconnected health services that include the pre-hospital emergency care, transportation of the injured persons to a health facility and the emergency medical care at the health facilities [4].

Pre-hospital emergency care is a lifesaving arrangement, which is provided to injured persons and those with acute illness in the field before arrival at a health facility. It is a chain of help, which is initiated by the victims themselves before other players such as the bystanders, and Emergency Medical Service (EMS) providers come in [5]. A review conducted by WHO on post-crash response with an intention of supporting those affected by road traffic crashes indicates that responders at the scene can identify individuals at the greatest risk of acute psychological stress [6]. In order to provide care to attain better outcomes in care of the casualties, prioritization is required.

A study conducted to determine the tyranny of distance and rural pre-hospital care in Australia found that 60 percent of rural clinicians at least triaged road accident victims before initiating treatment and transferring them for definitive care [7].

A study carried out on triaging of trauma cases in different countries found that paramedic rating of

Citation: Mathulu AW, Some ES, Ndonga EM (2021) Association between Pre-Hospital Prioritization and Outcome of Injuries from Road Traffic Accidents in Makueni County, Kenya. Trauma Cases Rev 7:095. doi.org/10.23937/2469-5777/1510095

Accepted: November 11, 2021: Published: November 13, 2021

Copyright: (C) 2021 Mathulu AW, et al. This is an open-access article distributed under the terms of the Creative Commons Attribution License, which permits unrestricted use, distribution, and reproduction in any medium, provided the original author and source are credited. 
the sensitivity of paramedic predictions for severe injury outcomes ranged from 57.6 percent (95 percent Confidence interval: $45.4,68.9)$ for the head to 38.5 percent (95 percent Confidence interval: 22.1, 57.9) for the abdomen. The study concluded that most trauma systems have not fully advanced trauma triage for optimal outcomes. However, the methodology applied in this study is not elaborated [8].

Another study that reviewed triaging systems for pre-hospital emergency medical services in Scandinavian countries shows that there is lack of scientific evidence about the effects of validated prehospital triage systems and the effects of using the same triage in two or more settings of an Emergency Medical Service. However, this study did not find any scientific documentation evaluating which triage system is more effective than the other in different settings in regard to health outcomes [9].

The history of Emergency Medical Services can be traced to the story of the Good Samaritan in the Bible [10]. Narrations on the ancient wars divulge a number of examples of structured methods of emergency care and transportation of the injured persons and the sick. Julius Caesar of the Roman Empire deployed battleground medics among his troops while Napoleons chief surgeons developed horse drawn wagons staffed with battlefield caregivers during the French revolution, which he called the Flying Ambulances [11]. The modern form of EMS came into operation between the end of 1960 and the early years of 1970 where organized transport and pre-hospital care was actualized [12]. There are two main pre-hospital emergency care forms as per the International Emergency Medicine that has been relied upon in formulation of the EMS System. These includes Anglo-American design (Emergency Medical Technicians (EMTs) and the paramedics, commence pre-hospital emergency care in the community and transfer the acutely ill or the injured person to the heath facility, where definitive care is provided) and the Franco-German Model (involves bringing the health facility to the critically ill, transferring the health workers and equipment to the scene of an incident with the intention of providing advanced care).

In the last fifty years, the developed countries such as the United Kingdom and the United States of America had designed elaborate systems for prehospital emergency care. In these countries pre-hospital emergency care is provided by professional rescuers while volunteers with basic life support training, provide care in the rural areas. There is a combined effort by the ambulance team and fire fighters who are normally the first to arrive at the incidence site. The ambulance team is normally well equipped and staffed by trained personnel who provide basic or advanced pre-hospital emergency care [12].

In Kenya, the limited pre-hospital emergency care, which is available, has mainly been provided by the private and the civil society organizations. The operations of these organizations have managed to cover Nairobi and only a few other urban areas. The main ambulance service providers in Kenya include Africa Air Rescue (AAR), St. John's Ambulance, Kenya Red Cross and the Africa Medical and Research Foundation (AMREF) Flying Doctors. The public health system has some ambulances stationed at and managed by hospitals mainly for referral of patients and sometimes respond to emergencies occurring within their catchment area [13]. In Makueni County, pre-hospital emergency care is provided through a hybrid system that combines the components of the Anglo-American and Franco-German models described above. A large proportion of care is initiated at the community by bystanders for various types of injuries ranging from minor to severe injuries.

A 2015 survey report on communicable disease factors in Kenya indicates that about 6 percent of Kenyans had been involved in road traffic accidents in the past 12 months. About 53.9 percent of these injuries necessitated medical treatment. Traffic related injuries have significantly contributed to hospital admissions and mortality in Kenya. In Kenya, traffic related injuries account for about 28 percent of the injuries sustained and are the $9^{\text {th }}$ leading cause of mortality [14].

In Makueni County, 900 road traffic injury related cases were treated in hospitals in Makueni in 2015. The police and hospital records further reported 74 traffic accident related deaths in the same period. In 2016, 550 injury cases were treated in the hospitals along the major roads in Makueni County [2,3].

Despite the prevailing circumstances, there has seen a disjointed response by the Good Samaritans and the emergency departments struggling to assist the persons experiencing emergencies. This often results to unnecessary loss of life and disability. However, majority of the guiding principles in response to road traffic accidents in Makueni are adopted based on research undertaken outside the County, which may not be applicable to the prevailing conditions here. This study therefore provides recommendations based on the local situation in Makueni and Kenya at large.

\section{Methods}

The researcher adopted the mixed methods approach and employed a cross-sectional study design between $17 / 10 / 2019$ and 15/5/2020. Under the mixed method approach, the researcher adopted the explanatory sequential strategy and begun by collecting quantitative data and followed with the qualitative component of the study to examine pre-hospital emergency care provided to persons inflicted with road traffic injuries in Makueni County and the corresponding outcomes until the desired sample was attained. The sample size was worked out as (using the formula by Fisher [15]; 
Formula:

$\mathrm{n}=\mathrm{z}^{2} \mathrm{pq} / \mathrm{d}^{2}$

Where:

- $\mathrm{n}=$ desired sample size (where population is greater than 10,000).

- $\mathrm{Z}$ = the standard normal deviate set at 1.96 which corresponds to the 95 percent confidence level.

- $\mathrm{P}=$ the proportion in the target population estimates to have a particular characteristic ( 50 percent (0.5): The proportion of First Responders in the population is not known and hence this will apply to enable the researcher obtain enough observations).

- $q=1.0-p$

- $\mathrm{d}=$ degree of accuracy desired, set at 0.05 .

Then the sample size was:

$\mathrm{n}=(1.96)^{2}(0.50)(0.50) /(0.05)^{2}$

$\mathrm{n}=384$

The calculated size was increased by 10 percent to ensure that the minimum sample is not affected by nonresponses. Hence the final sample size calculated was: $(10$ percent of 384$)=39+384=423$.

However, the actual sample obtained was about 427 First Responders who assisted 474 persons inflicted with road traffic injuries who were managed in six hospitals along Nairobi-Mombasa road, Makindu-WoteMachakos road and Tawa-Masii road, were selected for this study. The Responders were matched with the first person inflicted with injuries they assisted and who came for treatment in Makueni, Tawa, Makindu, Sultan Hamud, Kibwezi and Mtitoandei Hospitals. The casualties were categorized in the order through which they were assisted by a Responder. However, in order to establish the burden of injuries in the area, data was collected from all the casualties who received care in the area of study. The care provided during the pre-hospital phase and the outcome of the injuries sustained were confirmed from the First Responders, the patients and the medical records in various hospitals along the major roads in Makueni County where the casualties were transferred for definitive care.

Supervision of the Research Assistants enabled correction of errors and helped to reinforce the standards of the study. Comparison of observations (test-retest) of the same events (Construct being measured) among the trained Research Assistants ensured consistency of the findings. The consistency of responses in the questionnaire were tested through Cronbach's alpha test. The Cronbach's alpha reliability coefficient obtained was 0.765 . Any questions with a score less than 0.7 were removed. The data obtained was analyzed data through Statistical Package for
Social Sciences (SPSS Version 25). Missing data was checked through preliminary screening and filtering in excel sheet. Missing data was related to unobserved characteristics of the sample. Imputation model was used to randomly sample values of the missing data from their predicted distribution based on the observed data. The data was then checked for normality with the help of histogram, Q-Q plot and box plot which yielded approximately normally distributed data.

Frequency tables were used in presentation of findings. Cross tabulation was used to compare variables. Bivariate analysis explored the association between two variables. The chi-square was used for categorical variables such as gender in the demographic profile among the First Responders and the persons inflicted with injuries. Correlation was applied between various variables. Lambda measured association between nominal variables while Gamma and Pearson were used for ordinal and continuous variables respectively. A score of $= \pm 0.01-0.09$ was weak while $\pm 0.10-0.29$ was moderate. A strong association ranged from $\pm 0.30-0.99$.

Principal Component Analysis was used to group and summarize the variables into smaller number. Multivariate analysis was conducted on various variables significantly associated with the dependent variable in bivariate analysis and those which loaded in the principal component analysis. A multinomial logistic regression was performed to model the relationship between the predictors such as prioritization actions by First Responders and their socio-economic characteristics and their membership in the dependent variable which was labelled as mild, moderate or severe. The reference category was labelled as mild for the cases treated and released at the out-patient department. Likelihood ratio chi-square test was used to test the goodness of fit of the model. The $p$-value for the test was $<0.001$ hence indicating a better significant fit. The observed differences between Multinomial regression model and predictor variables were deemed to be statistically significant if the $p$-value was equal to or less than 0.05 . The results were shown by odds ratio (OR) with $95 \%$ confidence $(\mathrm{Cl})$. The wald test (and associated $p$-value was used to evaluate whether or not the logistic coefficient is different than zero and the odds associated with each predictor. The parameter estimates was indicated by the logistic co-efficient $\operatorname{Exp}(\mathrm{B})$ at $95 \% \mathrm{Cl}$ for each predictor variable for each alternative category of the outcome variable. There was assumption of independence among the dependent variable choices and that independence of observations and dependent variable had mutually exclusive and exhaustive categories. There was no multicollinearity and high outliers or highly influential points for the continuous variables. The predictors which had effect increased the logit to display $\operatorname{Exp}(B)$ greater than 1.0 while those which decreased the logit displayed Exp (B) score of less than 1.0. The predictors without effect displayed Exp (B) 
Table 1: Demographic and socio-economic characteristics of casualties.

\begin{tabular}{|c|c|c|c|}
\hline Variable & Values & Frequency & Percent \\
\hline \multirow[t]{2}{*}{ Gender $(n=474)$} & Male & 341 & $71.9 \%$ \\
\hline & Female & 133 & $28.1 \%$ \\
\hline \multirow[t]{2}{*}{ Age $(n=471)$} & $<30$ & 249 & $52.7 \%$ \\
\hline & $\geq 30$ & 222 & $47.1 \%$ \\
\hline \multirow[t]{2}{*}{ Marital status $(n=471)$} & Others & 211 & $44.8 \%$ \\
\hline & Married & 260 & $55.2 \%$ \\
\hline \multirow[t]{3}{*}{ Religion (471) } & None and others & 29 & $6.2 \%$ \\
\hline & Catholic & 168 & $35.7 \%$ \\
\hline & Protestant & 274 & $58.2 \%$ \\
\hline \multirow[t]{3}{*}{ Education level $(n=471)$} & None and primary & 122 & $25.9 \%$ \\
\hline & Secondary & 183 & $38.9 \%$ \\
\hline & Post-secondary & 166 & $35.2 \%$ \\
\hline \multirow[t]{4}{*}{ Main occupation $(n=471)$} & Farmer & 39 & $8.3 \%$ \\
\hline & Business & 120 & $25.5 \%$ \\
\hline & Employed & 160 & $34.0 \%$ \\
\hline & Unemployed & 152 & $32.3 \%$ \\
\hline
\end{tabular}

Table 2: Characteristics of first responders $(n=427)$.

\begin{tabular}{|l|l|l|}
\hline $\begin{array}{l}\text { Variables (n= 427) and } \\
\text { Values }\end{array}$ & Frequency & Percentage \\
\hline Gender & 301 & \\
\hline Male & 126 & $70.5 \%$ \\
\hline Female & & $29.5 \%$ \\
\hline Age (Years) & 132 & $30.9 \%$ \\
\hline$<30$ & 295 & $69.1 \%$ \\
\hline$\geq 30$ & & \\
\hline Marital status & 106 & $24.8 \%$ \\
\hline Others & 321 & $75.2 \%$ \\
\hline Married & & \\
\hline Religion & 28 & $6.6 \%$ \\
\hline None and others & 158 & $37.0 \%$ \\
\hline Catholic & 241 & $56.4 \%$ \\
\hline Protestants & & \\
\hline Education level & 85 & $19.9 \%$ \\
\hline None and primary & 180 & $42.2 \%$ \\
\hline Secondary & 162 & $37.9 \%$ \\
\hline Post-Secondary & 176 & \\
\hline Main occupation & 41 & 100 \\
\hline Farmer & & \\
\hline Business & & \\
\hline Employed & & \\
\hline Unemployed & & \\
\hline Total & & \\
\hline & & \\
\hline
\end{tabular}

of 1.0. The overall percentage of correct classification was $82.8 \%$.

\section{Results}

\section{Socio-demographic characteristics}

Casualties: Study findings in Table 1 show that, of the 474 casualties, $71.9 \%$ were males whereas $28.1 \%$ were females. Of the 471 casualties whose ages were confirmed, $52.7 \%$ were aged below 30 years. Those in the married group form the majority with $55.2 \%$. Majority $(58.2 \%)$ of the casualties were Protestants. The study findings further revealed that $38.9 \%$ of the casualties had attained secondary education.

First Responders: Table 2 indicates that First Responders were mainly young males, married and Protestants who were from a higher socio-economic class. Majority of First Responders were predominantly male $(70.5 \%)$ with majority $(69.1 \%)$ being above 30 years of age and married (75.2\%).

\section{Pre-hospital prioritization}

Table 3 shows that the First Responders mostly $(82.4 \%)$ prioritized those casualties who were seriously injured but who had a reasonable chance of survival. Those with minor cuts were the last $(0.7 \%)$ to be transferred to the health facility. This is echoed by majority of the Focus Group Discussions (FGD) discussants who said that "sometimes the casualties with minor injuries settle the issue before the police come and move to health facilities of their choice".

The most frequent $(72.4 \%)$ determiners of the health facility where the casualties were transferred to included other responders other than the ambulance team. This theme is referenced by participants in more than half of the groups who said that "depending on the means of transport the bodaboda (motorbike) riders 
Table 3: Prioritization of casualties $(n=427)$.

\begin{tabular}{|l|l|l|}
\hline Variable $(\mathbf{n}=\mathbf{4 2 7})$ & Frequency & Percent \\
\hline Priority for transfer to the health facility & & $3.7 \%$ \\
\hline Those with no apparent injury or with minor injuries & 16 & $82.4 \%$ \\
\hline Those seriously injured but have a reasonable chance of survival & 352 & $2.1 \%$ \\
\hline Deceased or those with serious head or chest injuries & 9 & $11.7 \%$ \\
\hline All patients & 50 & \\
\hline Destination determinant & & $72.4 \%$ \\
\hline Others & 309 & $27.6 \%$ \\
\hline Ambulance team & 118 & \\
\hline
\end{tabular}

Table 4: Prioritization of casualties at the site of accident.

\begin{tabular}{|c|c|c|c|c|c|c|c|}
\hline \multirow[t]{2}{*}{ Study Variables and Values } & \multicolumn{3}{|c|}{ Outcome at Disposition } & \multirow{2}{*}{$\begin{array}{l}\text { Total } \\
\text { (N\%) }\end{array}$} & \multirow[t]{2}{*}{$\mathrm{X}^{2}$} & \multirow[t]{2}{*}{ df } & \multirow[t]{2}{*}{ P-value } \\
\hline & $\begin{array}{l}\text { Mild } \\
\text { (n\%) }\end{array}$ & $\begin{array}{l}\text { Moderate } \\
(\mathrm{n} \%)\end{array}$ & $\begin{array}{l}\text { Severe } \\
(\mathrm{n} \%)\end{array}$ & & & & \\
\hline \multicolumn{8}{|l|}{ Help to first casualty $(n=427)$} \\
\hline \multicolumn{8}{|l|}{ Sorted the injured } \\
\hline Yes & $200(74.1)$ & $15(5.6)$ & $55(20.4)$ & $270(100)$ & \multirow[t]{2}{*}{34.833} & \multirow[t]{2}{*}{2} & \multirow[t]{2}{*}{$0.001^{*}$} \\
\hline No & $99(63.1)$ & $39(24.8)$ & $19(12.1)$ & $157(100)$ & & & \\
\hline \multicolumn{8}{|l|}{ Organized for transport } \\
\hline Yes & $232(75.1)$ & $30(9.7)$ & $47(15.2)$ & $309(100)$ & \multirow[t]{2}{*}{14.614} & \multirow[t]{2}{*}{2} & \multirow[t]{2}{*}{$0.0006^{*}$} \\
\hline No & $67(56.8)$ & $24(20.3)$ & $27(22.9)$ & $118(100)$ & & & \\
\hline \multicolumn{8}{|l|}{$\begin{array}{l}\text { Moved the injured person from } \\
\text { danger }\end{array}$} \\
\hline Yes & $218(71.5)$ & $29(9.5)$ & $58(19)$ & $305(100)$ & \multirow[t]{2}{*}{10.386} & \multirow[t]{2}{*}{2} & \multirow[t]{2}{*}{$0.006^{*}$} \\
\hline No & $81(66.4)$ & $25(20.5)$ & $16(13.1)$ & $122(100)$ & & & \\
\hline \multicolumn{8}{|l|}{$\begin{array}{l}\text { Observed vital signs of the } \\
\text { casualty }\end{array}$} \\
\hline Yes & $24(57.1)$ & $3(7.1)$ & $15(35.7)$ & $42(100)$ & \multirow[t]{2}{*}{11.304} & \multirow[t]{2}{*}{2} & \multirow[t]{2}{*}{$0.004^{*}$} \\
\hline No & $275(71.4)$ & $51(13.2)$ & $59(15.3)$ & $385(100)$ & & & \\
\hline \multicolumn{8}{|l|}{ Provided First-aid } \\
\hline Yes & $135(65.9)$ & $28(13.7)$ & $42(20.5)$ & $205(100)$ & \multirow[t]{2}{*}{3.567} & \multirow[t]{2}{*}{2} & \multirow[t]{2}{*}{0.17} \\
\hline No & $164(73.9)$ & $26(11.7)$ & $32(14.4)$ & $222(100)$ & & & \\
\hline \multicolumn{8}{|l|}{$\begin{array}{l}\text { Priority for transfer to health } \\
\text { facility }(n=427)\end{array}$} \\
\hline Those with minor injuries & $12(75)$ & $2(12.5)$ & $2(12.5)$ & $16(100)$ & \multirow[t]{4}{*}{10.493} & \multirow[t]{4}{*}{6} & \multirow[t]{4}{*}{0.105} \\
\hline The seriously Injured & $252(71.6)$ & $46(13.1)$ & $54(15.3)$ & $352(100)$ & & & \\
\hline The deceased & $5(55.6)$ & $0(0)$ & $4(44.4)$ & $9(100)$ & & & \\
\hline All patients & $30(60)$ & $6(12)$ & $14(28)$ & $50(100)$ & & & \\
\hline Total & $299(70)$ & $54(12.6)$ & $74(17.3)$ & $427(100)$ & & & \\
\hline Destination determiner $(\mathbf{n}=$ & & & & & & & \\
\hline Others & $230(75.7)$ & $23(7.6)$ & $51(16.8)$ & $304(100)$ & 28.561 & 2 & $0.001^{*}$ \\
\hline Ambulance team & $65(55.1)$ & $31(26.3)$ & $22(18.6)$ & $118(100)$ & & & \\
\hline Total & $295(69.9)$ & $54(12.8)$ & $73(17.3)$ & $422(100)$ & & & \\
\hline
\end{tabular}

Note: *Significant: $P<0.05$

take the casualties to the nearest facility while cars take them to Makueni County Referral Hospital". Half of the Key Informants agreed with the above theme and one said that "the doctor decides where the victim should be taken but when you land at the scene, you just take the casualties to the nearest hospital".

\section{Destination triaging}

Bivariate analysis was undertaken to determine association between site of accident and on-transit 
actions to health facility with the nature and outcome of injuries from road traffic accidents. The bystanders were the leading $(75.7 \%)$ destination determiners for those patients treated and discharge with mild injury outcomes. The destination for the highest number (18.6\%) of those with severe outcomes at the time of disposition was determined by the ambulance team. However, discussants in three FGD groups said that "we take to the nearest facility for the clinician to triage". The destination for the highest $(26.3 \%)$ number of patients discharged with moderate injury outcomes was determined by the ambulance team as shown in Table 4.

Further findings indicate that sorting of casualties resulted to higher severe cases (20.4\%) at time of disposition than those who were not sorted. Higher proportion of severe outcomes (20.5\%) was noted in cases where first aid was provided by the responders as compared to those who had not received any care.

Statistical tests indicate a significant $(P$-value $<0.05)$ relationship between, sorting the injured, organizing for transport, moving the injured from danger, observing vital signs of the casualty, destination triage determiner with outcome of injuries. The association between the easiest way to stop bleeding and the priority to transfer casualties to the health facility was weak $(r=0.025)$. There was a significant correlation between conveyance mode and destination triaging of the casualties $(r=$ $-0.922 ; \mathrm{P}=0.001<0.05)$.

\section{Association between physical injuries with prioritization of casualties}

Bivariate analysis was conducted on association between site of accident actions with nature and outcome of injuries. Table 5 shows that the destination for the highest proportion of casualties with superficial $(42.8 \%)$ and deep cuts (33.2\%) was determined by other responders other than the ambulance team. Inversely, the destination for the highest proportion of those with fractures $(38.1 \%)$, those with concussion $(11.9 \%)$ and those with internal injuries (8.5\%) was determined by the ambulance team.

Further findings indicate that the casualties with minor injuries accounted for the highest (75\%) number of those prioritized for transfer to the health facility and those who were treated and released with mild injury outcomes. Those with serious head or chest injuries produced the highest number $(44.4 \%)$ of patients with severe injury outcomes.

Destination triage determiner was significantly $(p<$ 0.05 ) related to fractures, dislocation, concussion with loss of consciousness and internal injury.

\section{Influence of site of accident prioritization actions}

Table 6 shows that sorting of casualties was more likely to result to severe injury outcomes (OR 6.447; $95 \% \mathrm{Cl}(1.249-33.289) ; \mathrm{P}=0.26)$. The casualties helped with breathing were less likely to end up with severe outcomes (OR $0.0195 \% \mathrm{Cl}(0-0.637)$; $\mathrm{P}=0.028$.

\section{Influence of socio-demographic characteristics of responders}

The patients assisted by First Responders without any formal education or those who had attained primary education were less likely to end up with moderate injury outcomes (OR. $0.11595 \% \mathrm{Cl}(0.019-0.428) ; \mathrm{P}=$ 0.002 ).

\section{Discussion of Findings}

\section{Prioritization of casualties}

The current study sought to establish the influence of prioritization of casualties inflicted with traffic related injuries on outcomes of injuries. Though majority of the responders were able to prioritize the seriously injured people to be transferred to the hospital this ended up with severe outcomes. This disagrees with a study conducted in accident black spots in Ghana which revealed that, only a small proportion correctly mentioned the triaging techniques for unresponsive traffic related casualties. The little knowledge by the responders may have resulted to complications amongst the casualties [16].

A study in Moi Teaching and Referral Hospital in Kenya found that triage skills were lacking even among the physicians and that experienced pre-hospital personnel are more skilled than specialists in hospital settings [17]. This is because of the working environment in the pre-hospital set up which is not as organized as in the health facility set up. The interventions at the pre-hospital set up requires simple skills but with high impacts. The basic life skills can be acquired through training and experience. The current study revealed that only a third of the responders had been trained on basic life support. It should be noted that identifying priority for care of traffic related cases by most of the First Responders based on clinical needs is likely to be difficult. Prioritization of casualties by the lay responders may apply other factors other than the clinical needs of the patient.

The study also disagrees with another study that reviewed triaging systems for pre-hospital Emergency Medical Service (EMS) in different Scandinavian countries. Study findings show that there is lack of scientific evidence about the effects of validated prehospital triage systems and the effects of using the same triage in two or more settings of an EMS [9].

Though the lay responders were able to prioritize the casualties, they relied on variables such as cries from the casualties which may sometimes give mixed signals in terms of severity of injuries. The severely 


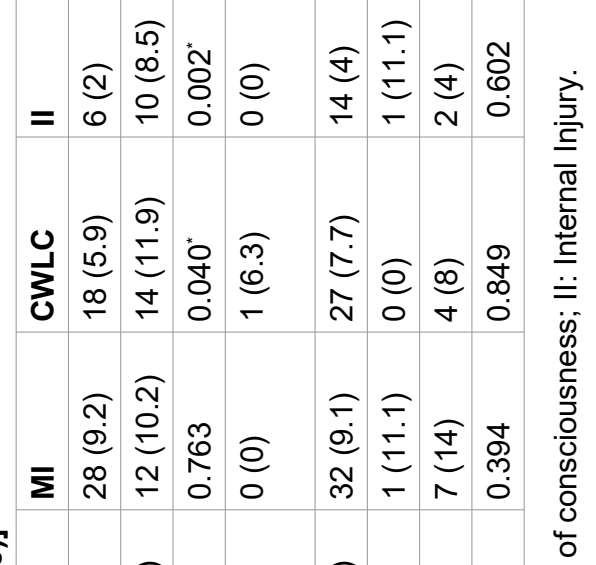

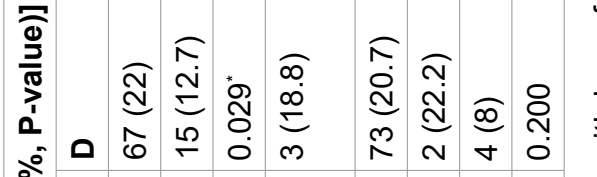

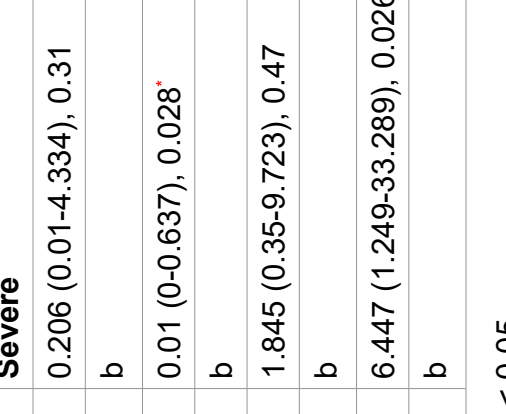

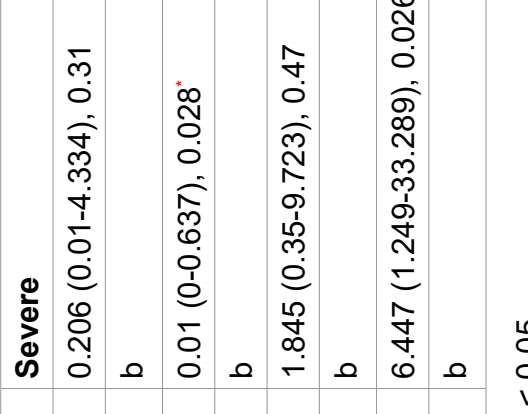

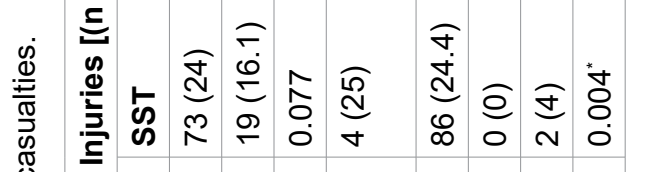

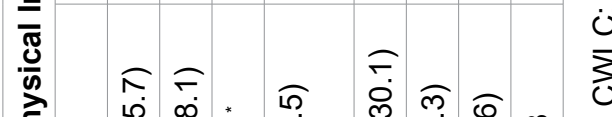

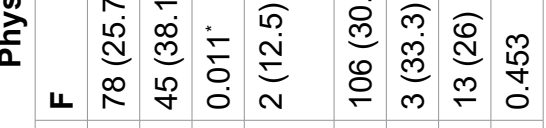

กิ่

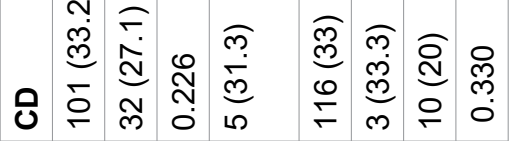

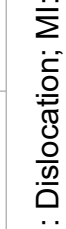

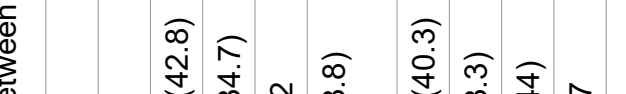

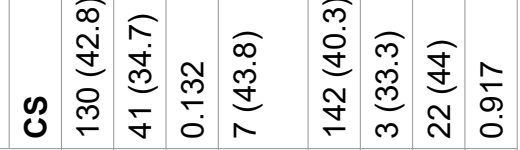

드

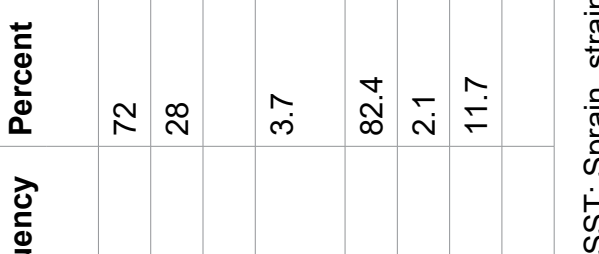

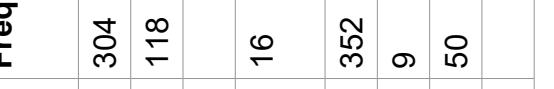
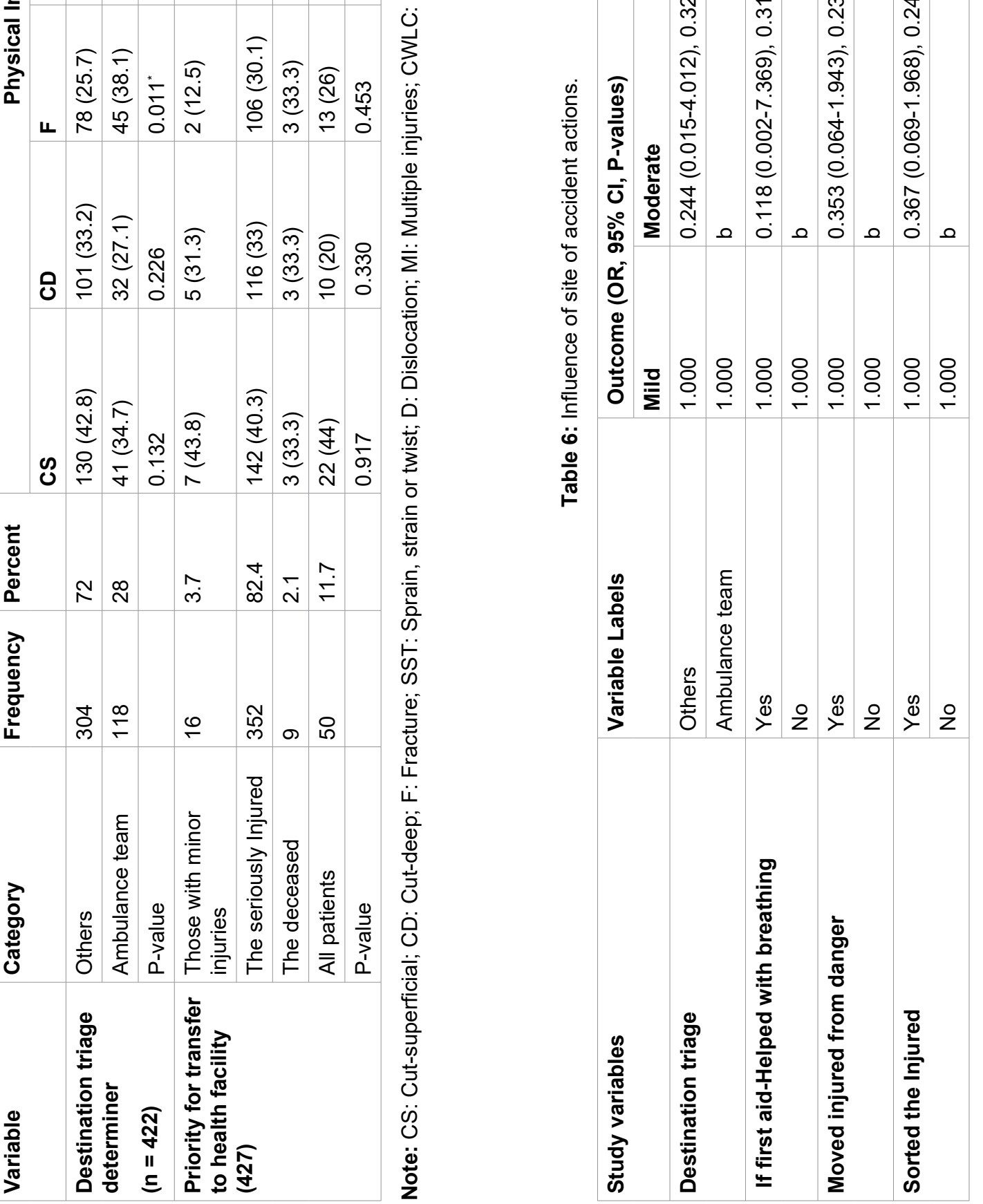

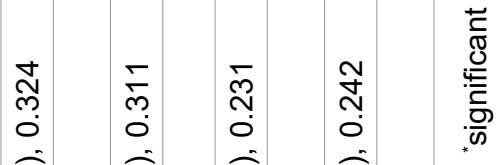
:

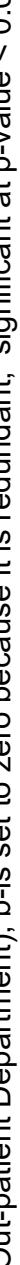

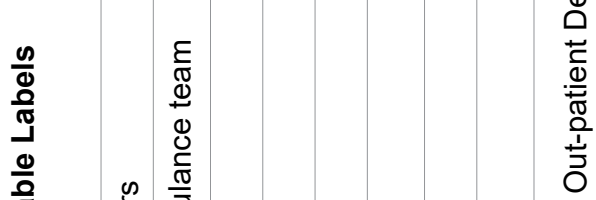

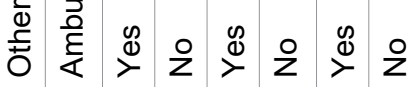

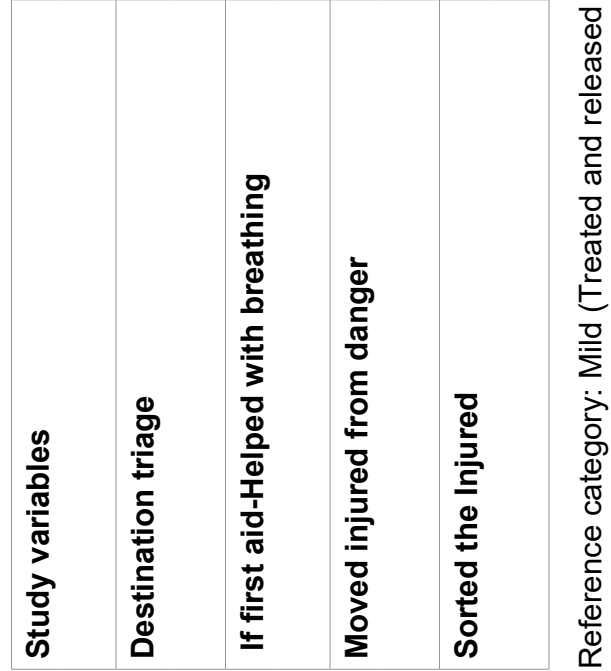


Table 7: Influence of socio-demographic characteristics of responders.

\begin{tabular}{|l|l|l|l|}
\hline Variable and Value Labels & \multicolumn{3}{|c|}{ Outcome (OR, 95\% CI, P-values) } \\
\cline { 2 - 4 } & Mild & Moderate & Severe \\
\hline Education level & & & \\
\hline None and Primary & 1.000 & $0.09(0.019-0.428), 0.002^{*}$ & $0.553(0.245-1.249), 0.154$ \\
\hline Secondary & 1.000 & $0.832(0.429-1.614), 0.586$ & $0.884(0.476-1.640), 0.695$ \\
\hline Post-Secondary & 1.000 & b & b \\
\hline
\end{tabular}

Reference (Mild: Treated and released at outpatient department); b (parameter is set to zero).

injured but quiet patients may be disadvantaged and are likely to be handled late. The lay responders in the pre-hospital settings may also attempt to apply anatomic or physiological data separately or in combination. However, this requires some training and experience. Therefore, there is need for scientific documentation indicating which triage system is more effective than the other in different settings considering resources availability experience of the personnel geographical location of an incidence and how this affects health outcomes. This means that prioritization of patients was not appropriate. As well, there was no communication to the receiving facility to prepare for the casualties.

\section{Conclusions and Recommendations}

This study sought to determine influence of prehospital triaging to outcomes of injuries from road traffic accidents in Makueni County, Kenya. This study concludes that: Prioritization of casualties, destination determination were significantly associated $(p<0.05)$ with outcome of injuries. The study recommends preparation of prioritization protocols for evacuation and destination triaging of casualties based on the assessment of patients' needs for better outcomes. Training of First Responders on first-aid and integration of first-aid into driving curriculum. Special emphasis should be on first aid care on air way, breathing and circulation, prioritization/ triaging of casualties.

\section{Acknowledgements}

I'm grateful to all whose contributions made it possible for me to accomplish this work. I wish to convey my gratitude to the staff of Mount Kenya University for providing me with the necessary guidance. I also wish to extend my gratitude to the Department of Health staff and all the Police commanders in Makueni County for their co-operation.

Last but not least, I'm grateful to the Research Assistants, the respondents and the community members living within various mapped black spots in Makueni and my peers for their invaluable information.

\section{Statement of Equal Authors Contribution}

A.W.M analysed and interpreted the data; E.S.S read, reviewed and approved the final manuscript; E.M.N read, reviewed and approved the final manuscript.

\section{Declarations}

\section{Ethics approval and consent to participate}

Ethical clearance was obtained from the Mount Kenya University Ethical Review Committee (MKU/ ERC/1352: Approval number 756) while National Council for Science and Technology and Innovation (NACOSTI) provided approval for data collection. Permission to collect data from the health facilities was obtained from the County Director of Health Services in Makueni.

The study is not experimental and hence consents for the use of any animal or human data or tissue, "Not applicable".

\section{Consent for publication}

Not applicable (The manuscript does not contain data for any individual person).

\section{Availability of data and materials}

The data used to support the findings of this study are available and can be provided by the corresponding author upon request (Anthony Wambua Mathulu: Corresponding author email: amathulu@gmail.com; mathulu@yahoo.com).

\section{Competing interests}

We as authors declare that we have no competing interests.

\section{Funding}

The corresponding author was the sole funder of the study. There was no external funding.

\section{References}

1. WHO (2015) Global status report on road safety 2015. World Health Organization, Geneva, Switzerland.

2. National Police Service (Makueni County)-Kenya (20132016) Accident reports. National Police Service, Makueni County, Kenya.

3. Department of Health-Makueni County (2015-2016) Health Management information system (HMIS) reports. Department of Health, Makueni County, Kenya.

4. Kironji A, Hodkinson $P$, Ramirez $S$, Anest $T$, Wallis $L$, et al. (2018) Identifying barriers for out of hospital emergency care in low and middle income countries: A systematic review. BMC Health Serv Res 18: 291.

5. WHO (2017) Save lives: A road safety technical package. World Health Organization, Geneva, Switzerland. 
6. WHO (2016) Post-crash response: Supporting those affected by road traffic crashes. World Health Organization, Switzerland.

7. Leeuwenburg T, Hall J (2015) Tyranny of distance and rural pre-hospital care: Is there potential for a national rural responder network. Emerg Med Australas 27: 481-484.

8. Cameron P, Gabbe B, Smith K, Mitra B (2014) Triaging the right patient to the right place in the shortest time. $\mathrm{Br} \mathrm{J}$ Anaesth 113: 226-233.

9. Lidal I, Holte H, Vist G (2013) Triage systems for prehospital emergency medical services-a systematic review. Scand J Trauma Resusc Emerg Med 21: 28.

10. Gideon's International (1978) The holy bible. National Publishing Company.

11. Minge, Erik D (2013) Emergency medical services response to motor vehicle crashes in rural areas. a synthesis of highway practice. National Academy of Sciences, Washington DC, USA.
12. Page C, Sbat M, Vazquez K, Yalcin ZD (2013) Analysis of emergency medical systems across the world. WPI.

13. $\mathrm{MOH}$ (2013) Concept paper on the proposed ambulance services in Kenya (a vision 2030 healthcare strategy). $\mathrm{MOH}$, Nairobi, Kenya.

14. $\mathrm{MOH}$ (2015) Kenya stepwise Survey for non-communicable diseases risk factors 2015 report. MOH, Nairobi, Kenya.

15. Fisher A, Laing J, Stoeckel J, Townsend JA (1998) Handbook for family planning operations research designs. (2nd Edn), Population Council, New York, USA.

16. Sam E, Blay D, Antwi S, Anaafi C, Adoma J (2019) Prehospital and trauma care to road traffic accident Victims: Experience of residents living along accident prone highways in Ghana.

17. Lamps M (2017) Triage management of the trauma patient. 